\title{
Supporting Communication Partners in a Leisure Setting to Enhance Social Interaction and Participation for Individuals with Complex Communication Needs
}

\author{
David Joseph Hajjar ${ }^{1,3}$, John Walter McCarthy', Molly Lanphear Hajjar ${ }^{2,4}$ \\ ${ }^{1}$ Communication Sciences and Disorders, Ohio University, $\mathrm{OH}_{;}^{2}$ Voinovich School of Public Affairs, Ohio University, $\mathrm{OH}_{;}^{3}$ Department of Speech- \\ Language Pathology and Audiology, Ithaca College NY; ${ }^{4}$ Department of Recreation and Leisure Studies, Ithaca College, NY, USA
}

Communication partners are critical supports for individuals with complex communication needs who participate in leisure activities. Partners (e.g., volunteers, program leaders, support staff) can enhance recreational experiences by facilitating opportunities for communication, interaction, and participation. In this study, a single subject multiple baseline design across two time periods was used to examine the accuracy of volunteers' in their ability to implement a program designed to promote communication and participation. Four volunteers from therapeutic riding learned to apply a communication program that focused on providing participants with a method to capture and share their riding experience. Results indicated that the volunteers successfully learned the program and that riders increased the amount of communication turns taken with volunteers. Volunteers, participants, and caregivers also shared their overall perspectives after program implementation. Implications and recommendations for future practice are provided for volunteers, participants and caregivers, recreational therapists, and other related professionals.

Keywords: Communication, Augmentative and alternative communication, Disability, Leisure participation, Quality of life, Engagement

\section{INTRODUCTION}

\section{Benefits from leisure and recreation}

Participation in recreational activities can have extensive benefits for children and adults with disabilities and complex communication needs (CCN) [1-4]. The infrastructure in recreation and leisure programs supports people who use augmentative and alternative communication (AAC) to develop relationships, increase engagement, and foster independence [2]. Opportunities for meaningful interactions are important for individuals with significant communication disabilities as they often report higher levels of loneliness and their social networks are more limited [5]. Patterson \& Pegg [4] determined that serious engagement in leisure activities provides people with intellectual disabilities the necessary confidence to communicate and teaches new skills that build self-esteem and facilitate social inclusion across community settings.

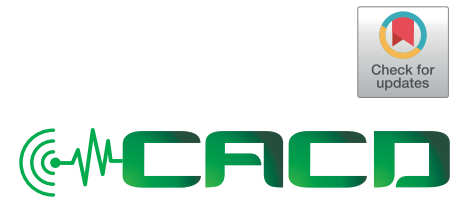

Received: October 2, 2018

Revision: December 11, 2018

Accepted: December 18, 2018

Correspondence:

David Joseph Hajjar

Department of Speech-Language Pathology and Audiology, School of Health Sciences and Human Performance, Ithaca College, Ithaca, NY 14850, USA

Tel: +607-274-7790

Fax: +607-274-1137

E-mail:dhajjar@ithaca.edu

Preliminary findings of this study were presented in 2016 at the International Society for Augmentative and Alternative Communication (ISAAC) Conference in Toronto, $\mathrm{ON}$.

C 2018 The Korean Association of SpeechLanguage Pathologists

This is an Open Access article distributed under the terms of the Creative Commons Attribution NonCommercial License (http://creativecommons.org/ licenses/by-nc/4.0/) which permits unrestricted noncommercial use, distribution, and reproduction in any medium, provided the original work is properly cited. 


\section{Active leisure pursuits}

Recreational activities such as adaptive skiing and therapeutic horseback riding are rich with opportunities for meaningful interaction and communicative exchange among program leaders, staff, volunteers, participants with disabilities, and their caregivers. Previous research has investigated the positive impact of adaptive recreation programs on improving quality of life and psychosocial benefits for people with disabilities [6,7].

Recreation and leisure programs have been identified as beneficial for individuals with disabilities and volunteers $[6,8,4,9]$. In a study surveying individuals with physical and cognitive disabilities, Zabriskie et al. [9], discussed the positive influence of leisure activities such as skiing and horseback riding on overall health, development of athletic identity, and increased quality of life. Hawkins et al. [8] conducted single subject research with children with autism spectrum disorder and determined that equine assisted therapy had positive effects on gross motor skills, specifically, body coordination, strength, and agility.

\section{Communication partners}

A common factor in recreational programs is the need for personnel support across the entire experience. Individuals who support people with disabilities become key communication partners and participation facilitators. Program leaders across leisure activities rely on volunteers and staff to support different aspects of the experience to ensure success and full participation. In the present study, volunteers from a therapeutic riding program were provided with training to facilitate communication exchanges with riders before and after their lessons.

Due to the type of activity combined with the unique skills and characteristics of each participant with a disability, several volunteers are often necessary to ensure a safe and enjoyable leisure experience. During the experience, volunteers become essential communication partners who create and enhance opportunities for interaction and social exchange. However, interactions with individuals who may be nonspeaking vary widely from interactions that occur with individuals who use natural speech [10].

Individuals with complex communication needs face barriers when interacting with partners across natural contexts as they may rely on AAC methods (e.g., gestures, tablets, vocalizations) that may be unfamiliar to most individuals. Some types of barriers include lack of facilitator skills and knowledge as well as negative societal attitudes [11,12]. In previous research, parents of children who use aided communication, discussed barriers such as impatient communication partners, limited opportunities for interactions with peers, and challenges using devices in outdoor settings [13].

For individuals with complex communication needs and physical disabilities, pre-planned supports and structure are necessary around the entire experience to ensure successful participation, community inclusion, and opportunities for frequent social exchange $[14,15]$. Research indicates that partners play a critical role in facilitating the success of individuals who have complex communication needs $[16,17]$.

\section{Volunteers in leisure and recreation}

Leisure and recreation programs rely on volunteers to ensure a safe and enjoyable experience. Volunteers play a critical role in ensuring the success of recreational experiences by focusing on each individuals' strengths and abilities. Hajjar et al. [18] interviewed volunteers from adaptive ski and therapeutic riding programs and found that most individuals came to the experience as a result of a shared lifelong interest and are willing and able to do more to create opportunities for communication. Lockstone-Binney et al. [19] discussed that volunteers make important contributions to activities of leisure as they engage in the process of assisting the experiences of others, while simultaneously undertaking a recreational activity themselves. The authors reported that volunteering may be looked upon as a key generator of social capital and increasing a sense of citizenship. Lastly, Collier et al. [20] determined that volunteer comfort levels towards individuals with disabilities increased after having exposure to therapeutic recreation programs.

The nature of adaptive recreational activities is such that many physical accommodations have been made to assist people with disabilities to access a wide range of sports and other activities. Volunteers, under the guidance of certified therapeutic recreational specialists and other related professionals, have been successful in making sport and outdoor activities physically accessible to individuals with a wide range of needs [21,22]. Many types of barriers have been eliminated, in large part because of the work of leisure and recreational professionals in settings of adaptive sport and outdoor recreation.

Supporting communication partners to enhance the experience There is limited research examining how communication partners support individuals with significant disabilities in leisure settings and their impact on enhancing communication, 
participation, and social interaction. Despite challenges related to limited time or lack of knowledge and skills, opportunities exist to empower leisure stakeholders to become more effective communication partners.

Kent-Walsh \& McNaughton [17] found that communication partners benefit from learning specific skills in a structured and systematic manner to be effective and to generalize skills in a natural manner with individuals who use AAC. In the present study, volunteers learned how to initiate and maintain a communication exchange that was embedded in the pre and post activity routine. The communication exchange focused on supporting riders to document and share their leisure experience. Through the communication exchanges, riders had greater opportunities to engage and participate as they were motivated to capture and share their meaningful experience with others.

\section{Research questions}

In this study, volunteers were provided with explicit instructions and training related to a novel intervention called the Take-home Program (hereinafter 'the program' or 'intervention program'). The purpose of the study was to investigate if volunteers could effectively learn and implement the program in the context of therapeutic riding lessons. This study sought to answer the following research questions:

1. How accurate were volunteers in the implementation of the program during pre- and post-lesson periods?

2. What was the effect of the program on the frequency of riders' communication turns in the pre- and post-lesson periods?

3. What were the perspectives of volunteers, participants, and caregivers relative to implementation of the program?

\section{METHODS}

\section{Research design}

A single-subject multiple baseline design over two distinct time points (e.g., pre-lesson period; post-lesson period) was used to evaluate the volunteers' ability to learn and implement the intervention program. Four volunteer/rider dyads participated in the study.

Previous investigations have used single-subject designs to investigate the effect of communication partners and the impact of partner intervention programs on individuals with complex communication needs [23]. In addition, a question- naire was used to get feedback from volunteers, riders, and caregivers.

\section{Participants}

Convenience sampling [24] was employed for this study as the selection of participants who were available were all associated and involved with the same riding program. All procedures performed in this study involving human participants were in accordance with the ethical standards with the Institutional Review Board at Ohio University in Athens, OH. Informed consent was obtained from all individuals and caregivers who participated in the study.

Participants included four adult volunteers and four riders with complex communication needs. Inclusionary criteria for adult volunteers were as follows: (a) volunteered with the same therapeutic horseback riding program located in Southeast Ohio, (b) were over 18 years of age, and (c) had at least a high school diploma or equivalent. The child and adult riders all met the following criteria; (a) were enrolled in two consecutive six week sessions, for a total of 12 weeks, (b) were age three or older, (c) presented with a complex communication need, meaning that per familiar caregiver report, the individuals' natural speech was not adequate to meet their daily communication needs with familiar or unfamiliar partners, (d) had hearing or vision within (or corrected to be within) functional limits, and (e) had receptive vocabulary skills at or above a 2-year developmental level as measured by the Peabody Picture Vocabulary Test (PPVT), fourth edition [25]. Table 1 includes demographic information for both volunteers and riders.

\section{Materials}

The following pieces of capture equipment were used in the study: (a) GoPro ${ }^{\circledR}$ Hero 4 camera and LCD screen; (b) Polaroid $^{\circledR}$ Instant Print camera; and (c) Sony ${ }^{\circledR}$ camcorders for taping pre- and post-lesson periods. In addition to the cameras, riders with disabilities could also select activity related items from a bucket. Bucket items were small toys or tangible items such as brushes for the horse, small plastic horses, or braided horse tails.

\section{Setting}

The study was conducted on a farm located in Southeast Ohio. The program served a variety of individuals with physical, mental, cognitive and communication disabilities. The riding instructor was a member of the Professional Associa- 
Table 1. Demographic information for volunteers and riders

\begin{tabular}{|c|c|c|c|c|c|}
\hline \multirow[b]{2}{*}{$\begin{array}{l}\text { Volunteer (name, age, highest } \\
\text { education, occupation) }\end{array}$} & \multirow[b]{2}{*}{$\begin{array}{l}\text { Rider (name, age, } \\
\text { year; month) }\end{array}$} & \multirow[b]{2}{*}{ Disability rider } & \multirow[b]{2}{*}{ Communication rider } & \multicolumn{2}{|c|}{ PPVT-4 - Riders } \\
\hline & & & & $\begin{array}{l}\mathrm{SS} \\
\mathrm{AE}\end{array}$ & Percentile \\
\hline $\begin{array}{l}\text { Jessica, } 31 \\
\text { Bachelor's degree } \\
\text { Job trainer }\end{array}$ & $\begin{array}{l}\text { Isaac } \\
3 ; 11\end{array}$ & Moebius syndrome & vocalizations, gestures & $\begin{array}{l}93 \\
3 ; 6\end{array}$ & 32 \\
\hline $\begin{array}{l}\text { Cindy, } 66 \\
\text { Bachelor's degree } \\
\text { Occupational Therapist (OT) }\end{array}$ & $\begin{array}{c}\text { Paul } \\
4 ; 4\end{array}$ & Childhood apraxia of speech & Natural speech, gestures & $\begin{array}{l}108 \\
5 ; 0\end{array}$ & 70 \\
\hline $\begin{array}{l}\text { Veronica, } 51 \\
\text { Bachelor's degree } \\
\text { Home inspector }\end{array}$ & $\begin{array}{l}\text { Beth } \\
21 ; 9\end{array}$ & $\mathrm{DD}$ & Natural speech & $\begin{array}{c}80 \\
13 ; 7\end{array}$ & 9 \\
\hline $\begin{array}{l}\text { Julia, } 43 \\
\text { H.S.\& } 3 \text { yr. college } \\
\text { Full time student }\end{array}$ & $\begin{array}{c}\text { Jill } \\
18 ; 2\end{array}$ & $\mathrm{DD}$ & Natural speech & $\begin{array}{c}76 \\
11 ; 4\end{array}$ & 5 \\
\hline
\end{tabular}

Pseudonyms have been used for all participants in the study.

OT, Occupational therapist; HS, high school; PPVT-4, Peabody Picture Vocabulary Test-4 (Dunn \& Dunn, 2007); DD, developmental disability; SS, standard score; $\mathrm{AE}$, age equivalent score.

tion of Therapeutic Horsemanship (PATH) International.

\section{Dependent measure}

The volunteer dependent measure was the number of steps successfully completed in the program during the pre and post-lesson period. For each pre- and post-lesson period, the number of steps accurately implemented in the correct sequence were observed. After program training, volunteers were expected to implement the program by following steps associated with a sequence of communication turns associated with different tasks. See Table 2 for a breakdown of the steps of the program, along with the volunteer tasks at each step. Volunteers were expected to follow the steps of the program and complete action items for each pre- and post-lesson period in the correct order working towards a total of 11 points. A point system was established to determine if volunteers were successful in following the sequence of the programs' steps and strategies.

The riders' dependent measure was the number of communicative turns they produced from baseline to intervention. Communication turns were analyzed post-hoc during 4-minute video segments in both the pre and post-lesson periods. Turns were counted during both the baseline and intervention phases.

\section{Procedure}

Data were collected during baseline, intervention and maintenance phases, while follow-up data were collected six
Table 2. Steps, tasks, and point values for tracking volunteer interactions

\begin{tabular}{lll}
\hline Steps & \multicolumn{1}{c}{ Action item } & \multicolumn{1}{c}{ Points } \\
\hline 1. Call & $\begin{array}{l}\text { Acknowledge rider } \\
\text { Announce opportunity to select } \\
\text { take-home item }\end{array}$ & 1 \\
2. Choose & $\begin{array}{l}\text { Offer three choices } \\
\text { Label each choice } \\
\text { Respond to rider }\end{array}$ & 3 (1 point for each item) \\
3. Confirm & $\begin{array}{l}\text { Repeat the item and review with } \\
\text { rider }\end{array}$ & 1 \\
& $\begin{array}{l}\text { Ask a question based on the } \\
\text { item selected }\end{array}$ & 1 \\
4. Consider & $\begin{array}{l}\text { Respond to the rider } \\
\text { 5. Capture }\end{array}$ & $\begin{array}{l}\text { Ask a question based on the } \\
\text { item selected }\end{array}$ \\
& $\begin{array}{l}\text { Respond to the rider } \\
\text { Provide a compliment based on } \\
\text { the item selected }\end{array}$ & 1 \\
\hline
\end{tabular}

months after the final maintenance session. The pre-and postlesson periods were considered two distinct time periods with different activities and tasks conducted during each riding lesson. For example, in the pre-lesson period, the riders would greet and groom their horse in preparation for mounting and riding. However, during the post- lesson period, the rider was sitting on the horse with the volunteer providing side walking or lead support while engaged in a closing activity.

All dyads were videotaped during baseline and intervention sessions for both the pre- and post-lesson periods. The pre- 
lesson period started once the rider entered the indoor ring and ended once the rider was preparing to mount the horse. Post-lesson periods occurred while the rider was still on the horse, starting with the introduction of the closing activity and finishing once the rider exited the ring after saying good-bye to their horse and volunteers.

\section{Baseline phase}

A minimum of three baseline probes were collected for each dyad during the pre-lesson sessions and a minimum of six baseline data collection sessions were conducted during the post-lesson period. The baseline probes for the pre-lesson period were collected once a week, for three consecutive weeks prior to instructing the volunteers about the intervention program. Baseline probes for the post-lesson period were collected once a week for six consecutive weeks prior to training the volunteers to use the program during the post-lesson period.

\section{Instructional phase}

After a stable baseline was achieved during the pre- and postlesson periods, the Take-home program was taught to each of the volunteers. The eight-step partner instruction model described by Kent-Walsh \& McNaughton [17] was used as a guide for developing the training. The training included an explanation of the program with a description, demonstration, guided practice and feedback provided at each step. The first training was conducted after a stable baseline was achieved in the pre-lesson periods and the second training session was conducted after a stable baseline was achieved in the post-lesson periods.

Group training sessions lasted for approximately 2 hours. Using role plays, volunteers were trained when to provide repetition of the target questions based on the type of response, absence of response, or delayed response produced by the rider. They were also instructed to use an expectant delay after providing choices or asking questions while implementing the program. During the training, volunteers were encouraged to ask clarifying questions or generate other spontaneous comments in addition to the program script. Volunteers received feedback on their performance from the first author as needed. Lastly, instructions about operational tasks for each device (e.g., cameras) were also provided as needed.

\section{Maintenance phase}

To monitor the volunteers continued use of the intervention strategy and the riders' appropriate responses to additional communication opportunities, maintenance probes were conducted four and five weeks following completion of the intervention training for the pre-lesson period and four and six weeks after the instructional training for the post-lesson period.

\section{Six-month follow-up}

A follow up session was conducted in the spring riding season, which occurred approximately 6 months after the completion of the study. One of the volunteers was not available to participate in the follow up session as she was no longer volunteering with the program.

\section{Coding and scoring}

Video of the volunteer and rider dyads were analyzed for a total of 4 minutes in both the pre-and post-riding periods for a total of 8 minutes of analysis. Video was transcribed across twelve sessions for each rider across both the pre-and postlesson periods ( 6 baseline and 6 intervention). A total of 72 minutes was analyzed for each dyad with a focus on the two dependent variables: (a) the volunteers' accurate completion of each step of the intervention program and (b) the amount of communicative turns that occurred for riders during baseline and intervention sessions.

\section{Volunteers}

To track the volunteers' implementation of the intervention program, the primary investigator and research assistants (i.e., scorers) watched the videos and scored the volunteers according to their ability to accurately follow the steps and strategies. The volunteers were expected to implement the steps of the program for each pre- and post-lesson period; but, at times had to adjust and modify implementation based on the current activity, rider responses, and the specific choice made by each of the riders. The scorers used a rubric to track the volunteers' performance as they could earn up to a total of 11 points. See Appendix A for the scoring rubric.

\section{Riders}

Communicative turns were only coded when the riders directed a turn to the lead volunteer. All turns were coded as responses or initiations within three different topic categories (i.e., program related, horse related, or other). Using definitions from Datillo \& Light [16], communication turns of riders were defined as intentional acts directed toward the volunteer, including speech or speech approximations, gestures (e.g., 
head nod, shake, point), and output from AAC systems, including print or visual symbols. Initiations were defined as the first turn in a conversation, introduction or change in topic or a turn followed by a pause of more than 2 seconds with no response form the partner.

\section{Reliability}

\section{Volunteer accuracy completing program steps}

The principal investigator completed all initial scoring using the scoring rubric. To calculate data reliability on this dependent variable a graduate research assistant analyzed $20 \%$ of the data. The research assistant independently viewed a total of 16 video segments and rerecorded the data without reference to the original data. The research assistant was blinded to the condition for each video. Cohen's kappa [26] was used to calculate interrater reliability for rater agreement in tracking the volunteers' ability to accurately complete steps and strategies of the program. Kappa was calculated at 0.952 . The results indicated an almost perfect agreement between the principal investigator and the research assistant.

\section{Rider communicative turns}

A second graduate research assistant independently completed an analysis of $25 \%$ of the data with a focus on tracking the number of communicative turns (e.g., responses or initiations) from each rider during each 4-minute video segment. See Appendix B for operational definitions relative to types of communication turns. For each dyad, the graduate assistant viewed video segments and transcripts simultaneously and rerecorded the dependent variable data without reference to the original data. The graduate assistant viewed a total of three video segments for each dyad and was blinded to the specific phase (i.e., baseline or intervention). Cohen's kappa was used to calculate interrater reliability for the rider data which was 0.913 . This indicated an excellent agreement between the principal investigator and the research assistant for data relative to the number of communicative turns across a 4-minute period at baseline or intervention for each rider.

\section{Data analysis}

The dependent measure for the volunteers was graphed and visually inspected for changes in trend, slope, and level of the data [27]. Also, improvement rate differences (IRD) were calculated to compare the baseline phase to the intervention phase. The dependent measure for the riders, the frequency of communicative turns, was presented in a table outlining the frequency of communicative turns that occurred during baseline and intervention phases.

\section{Social validation}

To ensure social validity, a brief questionnaire was given to the volunteers to obtain their feedback. The brief survey included questions regarding their satisfaction with the program and whether they would participate in the program again. A similar questionnaire was provided families and caregivers. The two riders who were over age 18 also completed a questionnaire with the assistance of their caregiver.

\section{RESULTS}

\section{Volunteers}

The data are presented for the volunteers' acquisition and maintenance of the program from baseline to intervention phase. The program served as a type of enhancement intervention that allowed the lesson to continue naturally while also providing the rider an opportunity to capture their experience. The dependent measures for the volunteers were graphed and visually inspected for changes in trend, slope, and level of the data. Figures 1 and 2 show the volunteers' successful acquisition and application of the program. Figure 1 shows the results from the volunteers Cindy and Jessica who supported the two child riders and Figure 2 shows the results of Julia and Veronica who supported the two adult riders.

Volunteers received points for each step of the program that was successfully completed in the correct order. A maximum of 11 points could be earned. All volunteers used the program with at least $80 \%$ accuracy or above during the first three intervention sessions in both the pre- and post-lesson periods. The volunteers continued to use the program with high levels of accuracy during the maintenance and follow up periods. Three out of the four volunteers achieved $100 \%$ accuracy with program implementation six months after the final maintenance session. One of the volunteers was unable to participate in the follow up data collection session due to a scheduling issue.

Upon visual inspection of the figures, there was $100 \%$ nonoverlapping data points between the baseline and intervention phases for all the volunteers, demonstrating a strong effect of the instructional strategy. The IRD between the baseline phase and the intervention phase for each volunteer was calculated at 1 or $100 \%$ improvement from baseline, indicating strong effects [28]. Baseline performance was stable for all volunteers with minimal variability and no upward trend. Fur- 


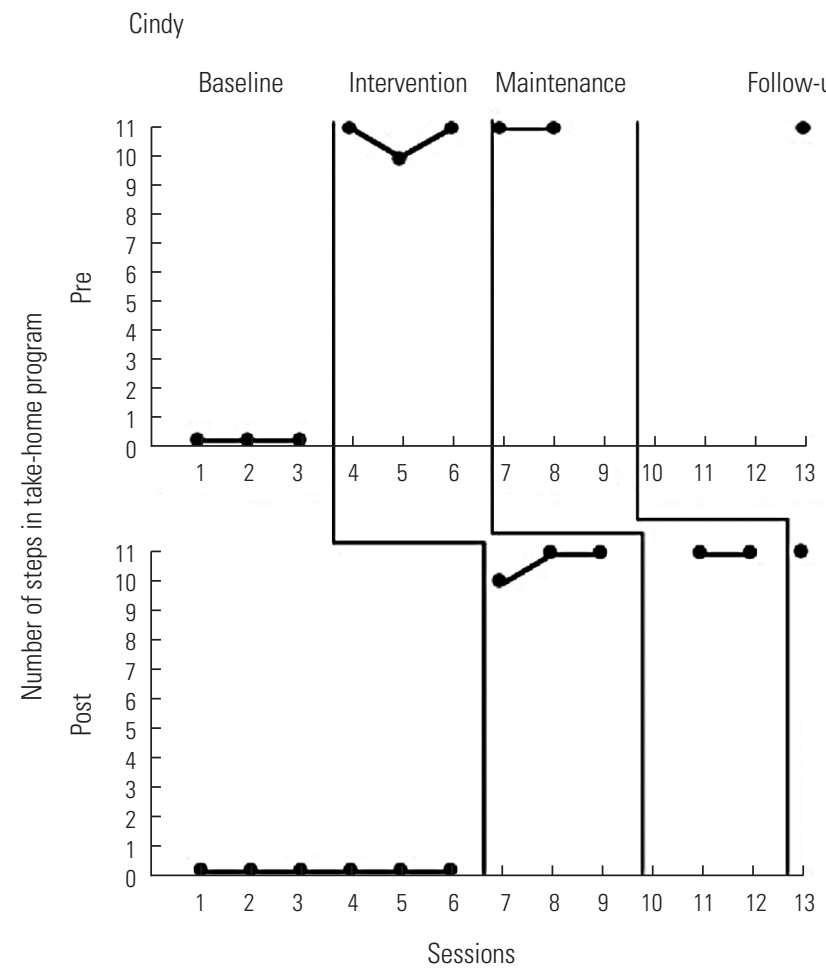

Jessica

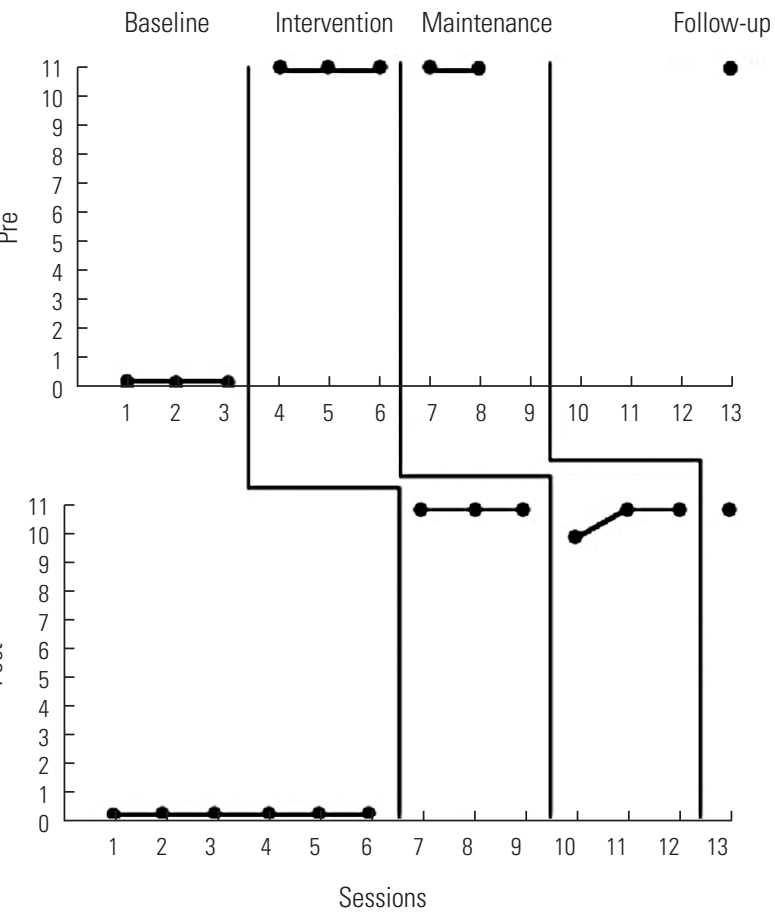

Figure 1. Total number of steps successfully achieved in the Take-home program (out of 11) by two different volunteers (Cindy \& Jessica) working with child riders during pre and post lesson periods. The first solid line between baseline and intervention indicates when the training occurred.



Veronica

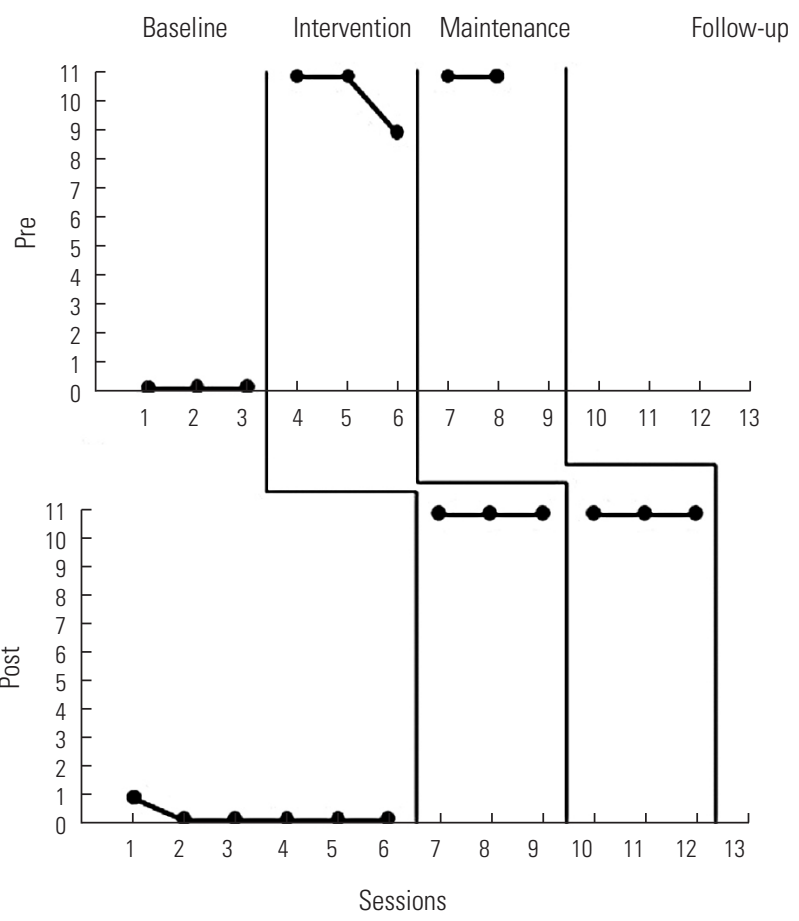

Figure 2. Total number of steps successfully achieved in the Take-home program (out of 11) by two different volunteers (Julia \& Veronica) working with adult riders during pre and post lesson periods. The first solid line between baseline and intervention indicates when the training occurred. 
thermore, there was a significant increase in level between baseline and intervention phases for all volunteers.

\section{Riders}

The number of communicative turns that occurred for each rider were counted based upon the coding criteria previously described. Riders' communication turns were counted before and after implementation of the intervention program. Responses and initiations were counted and grouped by topic (e.g., horses, program, other). The number of turns for each rider were combined for the baseline phase and the intervention phases. See Table 3 for the difference in the number of combined communication turns that occurred from baseline to intervention for each rider.

Based on the frequency count, it is evident that all riders demonstrated an increase in the number of responses and initiations they produced during baseline to intervention sessions. After the volunteers started to implement the program, additional communication opportunities were provided to the riders and as a result, an increase in the number of responses and initiations was found. The riders took advantage of the increased opportunities for communication as they worked collaboratively with the volunteers to capture their lesson using cameras or selecting a preferred take home object. All four riders (two children and two adults) demonstrated an increase in their communicative turns from baseline to intervention.

\section{Social validation}

Three out of the four volunteers indicated they would use the program again as a therapeutic riding volunteer. One volunteer indicated she would not use the program again as she had some difficulty with using the technology. Through the completion of questionnaires, all parents and caregivers indicated that they thought the program was valuable and as a result had shared specific artifacts (e.g., photos, videos, horse related item) with friends or family members.

The two adult riders also completed questionnaires at the

Table 3. Number of communicative turns at baseline and intervention

\begin{tabular}{lcc}
\hline Rider & Baseline & Intervention \\
\hline Paul & 66 & 106 \\
Isaac & 79 & 120 \\
Beth & 98 & 145 \\
Jill & 68 & 91 \\
\hline
\end{tabular}

end of the study and indicated that they enjoyed participating in the program. One of the adult riders consistently selected the take home items/objects to share with her family and collect in her room. The other adult rider enjoyed taking photos and videos and having her lesson recorded so that she could share this with her family.

\section{DISCUSSION}

There were many factors that led to the volunteers' successful use of the intervention program. Leisure participants (both volunteers and riders) shared a meaningful experience while working together to document various aspects of the activity. Motivated volunteers achieved a high level of competency when using the program during the pre-and post-lesson periods and riders increased their overall number of conversational turns. Caregivers and riders with disabilities reported benefits relative to enjoyment and sharing of the collected artifacts (e.g., photos, videos, or horse related objects) with people in their social networks. Finally, the setting and the sequence of the lesson were also important factors that led to the success of program implementation.

Three primary factors: (a) volunteers as communication partners; (b) intervention program scope and sequence; and (c) type of leisure activity and setting, are discussed relative to their impact on how volunteers implemented the program. Additional implications, recommendations, limitations of the study and future research directions will also be discussed.

\section{Successful program implementation Volunteers as communication partners}

The results of the study provided support for training volunteers who facilitate therapeutic riding with children and adults. The four volunteers effectively learned to use the program with their assigned riders following a relatively brief period of training (approximately 2 hours). In each case, the volunteers met criterion ( $80 \%$ accuracy completing steps) within two intervention sessions.

Volunteers were critical to the success of the program as they were committed communication partners who were willing to learn more to enhance the riding experience and support greater opportunities for communication. They were present and available for all baseline and intervention sessions which demonstrated a strong level of commitment to the program and their role in facilitating the riding experience. Also, volunteers were open to learning about the pro- 
gram and were skilled in being able to integrate the program into the pre- and post-lesson periods. Furthermore, all the volunteers in this study had previous experience working with horses and were passionate about sharing their leisure interest and knowledge with other individuals. Due to the volunteers' comfort with horses and their high level of familiarity with the environment, this allowed them to successfully integrate the program into the pre-and post-lesson periods.

\section{Program scope and sequence}

The intervention program was developed by the investigators to enhance the riding experience by creating more opportunities for communication and providing a method for riders to document and share the activity with people in their social networks. The program did not fundamentally change the lesson procedures, but instead enhanced the relationship between volunteers and riders as it provided an additional reason for both individuals to communicate and engage about a shared task. The results of the study showed that it is possible for more communication opportunities to be integrated without changing the nature of the leisure activity or program.

Volunteers were successful with implementing the program because it provided a balance of scripted and spontaneous language, was simple and systematic, and generated increased opportunities for sharing, communication, and full participation.

The program contained a combination of scripted utterance based communication paired with key strategies for facilitating natural interactions (e.g., expectant delay, choice making). This provided the communication partner (i.e. volunteer) with adequate structure and clear expectations for completing the program elements, but also allowed them to keep the interaction as natural as possible. The program script served as a support for the volunteers to initiate and maintain a conversational exchange throughout the interaction.

Next, the program was simple, systematic and easy to implement. The volunteers participated in one training session and had an opportunity to review the conversational script on their own time. Also, since the script was similar in both the pre- and post riding periods, the volunteers had sufficient practice following the program sequence. The items used in the program (e.g., cameras) were the same from session to session, so volunteers were able to become familiar with the operational demands of the technology.

Lastly, the program provided opportunities for additional conversational exchange and social interactions among vol- unteers, riders and caregivers. Since the program provided a tangible outcome (i.e., photo, video or object) this led to increased sharing and additional conversational turns. Several caregivers also reported that sharing of artifacts extended into the home and educational setting as well, creating increased opportunities for social connection through leisure experiences.

\section{Type of leisure activity and setting}

The therapeutic riding setting was selected due to the existing lesson infrastructure which had two distinct time periods (e.g., pre- and post-lesson period). The intervention program was implemented in a manner that did not interfere with the leisure activity. The program was designed to be used across a broad range of recreational settings that may be enhanced or made accessible with support from communication partners (e.g., recreational therapists. program leaders, volunteers, or support staff). In this study, the riding lesson provided an appropriate structure for implementation of the program without the need to interfere with teaching methodology or skill instruction specific to the activity. Also, the riding lessons were conducted in an indoor ring, which made it easier to control the various options for documenting the lessons. Furthermore, parents and other caregivers could watch the lesson and were available for the riders to share their digital media artifacts upon lesson completion. Lastly, the riding activity was filled with many opportunities for digital media collection which is the case with a wide range of recreational activities.

\section{Riders communication}

A variety of factors may have contributed to the increase in the riders' communication turns during pre- and post-lesson periods. Three of these factors are: (a) more opportunities for communication turns; (b) increased motivation of the rider; and (c) full rider participation while completing the steps of the program. In addition to the riding lesson, the program supported opportunities for additional shared meaning and communication to occur between volunteers and riders. The dyads worked together to document the experience in a manner that encouraged participation and provided increased opportunities for social exchange. During implementation of the program, the riders needed to make choices related to the method of documentation and what they would like to document (i.e., horse, ring, volunteer, etc.). The additional task of documenting the experience allowed the volunteers another way to connect with the riders and provided opportunities for 
communication and interaction that did not previously exist.

Also, the program went beyond teaching facilitative interaction techniques (e.g., building in wait time after question, asking mixed wh-questions) by also providing a meaningful process to assist riders to collect personalized artifacts (i.e., photos, videos and activity related items). The process of collecting artifacts was integrated in a manner that supported full participation and greater communication from riders. During implementation of the program, the riders were motivated to engage and share in the experience. They enjoyed selecting and holding the cameras and other items when making choices and using the equipment to capture their experience. Riders were further motivated by the tangible outcomes from the program which included photos, videos, or activity related items. During program implementation, each dyad engaged in a collaborative and nonintrusive process that enhanced the riding experience while also creating more opportunities for communication.

\section{Implications of findings}

To reduce barriers, maximize benefits, and realize the full potential of the program, implications are presented for: (a) individuals with complex communication needs, (b) volunteers and leisure professionals, and (c) leisure and recreation programs.

First, individuals with complex communication needs who participate in the program will have more opportunities for communication and interaction when engaged in leisure activities. As a result of collecting personalized artifacts and items during leisure activities, individuals will gain specific artifacts that can be used to share and communicate with people in their social networks. The use of objects and visuals can assist people with complex communication needs to recall, reflect, and share experiences in a manner that encourages partners with similar interests to engage and aid in the coconstruction of messages.

Next, volunteers and related professionals in leisure and recreation will gain additional skills to be more effective communication partners. By training partners to support communication and participation, they will have greater awareness of how to facilitate interactions and encourage more independence and participation in other types of leisure and recreation activities. Trained communication partners could serve as mentors to new staff and volunteers, by educating them about communication and modeling ways to create opportunities to support social interaction and full participation. Ad- ditionally, lead staff or volunteers could work to establish a broad culture of communication and social exchange across leisure settings.

Finally, leisure and recreation programs will gain a network of trained individuals who understand the importance of focusing on communication to increase participation and enhance interpersonal connections. With additional training and collaboration with speech-language pathologists, recreation programs could have volunteers and staff that are more knowledgeable, skilled and able to effectively create an environment that provides natural opportunities for communication. In addition to their traditional roles, volunteers and staff can become communication and participation facilitators at different levels as they support access to leisure activities.

If volunteers and staff feel more comfortable in their own interactions with individuals with complex communications needs, they are poised to become role models and more effectively facilitate communication, and meaningful participation. Additionally, the frequency of communication with caregivers, family members and other related stakeholders may increase as they have an additional purpose to support participation and performance through sharing artifacts. More consistent communication between volunteers and caregivers may build greater trust between stakeholders and may result in additional communication opportunities outside of the activity environment. For example, leisure programs may enhance their overall services by offering consumers an opportunity to document and capture their meaningful experiences using media (i.e., photos and video) and activity related objects.

\section{Recommendations}

Communication and leisure professionals should create more opportunities for collaboration and interprofessional practice. Interprofessional experiences can be beneficial for both professionals and individuals with disabilities. Leisure settings provide many natural opportunities for communication and social interaction. Therefore, implementing strategies to facilitate social connections through interdisciplinary collaboration between speech-language pathologists and recreational therapists may enhance benefits experienced by participants with disabilities.

The following recommendations have been generated for leisure professionals and program administrators who rely on staff and volunteers to support adaptive sport and recreation programs. Those who support participation in leisure activi- 
ties (directors and volunteers) are in a position to assist and enhance the social and emotional health of individuals with disabilities who may have complex communication needs.

Leisure activities promote psychosocial skills which can have an important impact on communicative competence for people who use AAC. Psychosocial factors, such as confidence, motivation, and resiliency, are essential skills for people with complex communication needs to develop and apply [29]. Communicative competence is defined across four key areas: linguistic, social, operational and strategic. For an individual who uses AAC, this means that they can effectively use a language system, understand social roles in a conversation, repair communication breakdowns and use technology as needed.

By supporting communication through engagement, volunteers provide opportunities for interactions and participation that allow for a reciprocal social exchange. These consistent interactions can lead to relationships with others that may range from the level of casual acquaintance to friend. Overall, by having partners implement simple strategies throughout the experience, it can have a positive impact on improving communication, expanding social networks and increasing psychosocial skills.

The program used in this study was developed to assist volunteers to reflect on their own communication skills while also supporting increased opportunities for engagement with people with disabilities. The steps and strategies of the program provide a clear framework for volunteers. See Table 4 for specific recommendations for volunteers and support staff to more effectively engage, interact, and communicate with participants with disabilities before, during and after leisure and recreation experiences.

\section{Limitations and future research directions}

There were some limitations to the current investigation. One drawback of the investigation was related to the timing of the post-lesson baseline periods and pre-lesson intervention time periods. Since there were a limited amount of therapeutic riding lessons that were offered to each rider during the research timeline, it was critical to design the study using the two distinctive time periods that occurred in each lesson. As a result, some post-lesson baseline data collection sessions occurred at the same time as the pre-lesson intervention sessions. It was possible that the volunteers' performance in some postlesson sessions were influenced by their understanding and use of the program in the pre-lesson intervention periods
Table 4. Strategies for volunteers to increase participation and enhance communication

\begin{tabular}{|c|c|}
\hline Communication area & Strategy \\
\hline Expressive language & $\begin{array}{l}\text { Provide choices throughout the activity } \\
\text { Establish signals and consistent yes/no } \\
\text { Support use of multimodal methods and AAC } \\
\text { systems } \\
\text { Practice observational commentary } \\
\text { Assign lead volunteer to initiate communication }\end{array}$ \\
\hline Receptive language & $\begin{array}{l}\text { Provide adequate wait time between exchanges } \\
\text { Use clear concise language } \\
\text { Presume competence } \\
\text { Engage at eye level } \\
\text { Assign lead volunteer to respond to } \\
\text { communication } \\
\text { Minimize or eliminate extraneous conversation }\end{array}$ \\
\hline Social interaction & $\begin{array}{l}\text { Facilitate exchanges with the general public } \\
\text { Capture moments with digital media } \\
\text { Support sharing experiences with caregivers } \\
\text { and peers } \\
\text { Generate opportunities for reciprocal } \\
\text { communication }\end{array}$ \\
\hline
\end{tabular}

even though the time periods were distinctly different. Also, caution should be taken in generalizing results to all riders with complex communication needs who may use AAC. There were four riders in the current study and although they used multiple modalities for expression, three of the participants were able to use some natural speech for communication. It is important to consider the multimodal nature of communication and how this can impact the conversational exchange.

Future research directions include considering how to train and support volunteers and related stakeholders in other types of community based settings and programs. Also, it would be useful to think about other benefits and outcomes that may occur from training volunteers to enhance and improve communication and interaction. For example, it is likely that the program increased opportunities for communication, but it would also be beneficial to consider social and participation outcomes in relation to the acquisition of communicative competence for people with significant disabilities. Next, it would be important to investigate how participants use items and artifacts from recreation and leisure in other aspects of their life. For example, would participants use the items to facilitate shared meaning and make additional social connections with peers, classmates, and others who have similar interests? Finally, it would be important to consider the individual psychosocial benefits from leisure activities 
and how these may directly impact communicative competence for people who use AAC. Many of these future research directions would involve collaboration between leisure and recreation professionals and speech-language pathologists.

\section{CONCLUSIONS}

Communication partners across leisure and recreation settings are important to consider when supporting people with complex communication needs. It is critical to consider the needs of partners as their knowledge and skills are essential extrinsic factors that can positively influence social interactions and communicative competence [30]. The present study provides evidence that volunteers from a therapeutic riding program effectively and accurately implemented a program to support increased opportunities for communication and participation with children and adults with complex communication needs. The intervention program was developed to not only enhance the recreational experience for volunteers and riders, but also provide these individuals with increased opportunities for communication and sharing.

\section{ACKNOWLEDGMENTS}

The authors would like to thank the following individuals who assisted with the project: Jamie Boster and Kara Kuykendall. The authors would also like to thank Jackie Fokes and Lisa Bonner from Windy Hill Farm in Athens, Ohio as well as the volunteers, riders and their caregivers who participated in the project.

\section{Funding}

This research was supported by funding from a Community Engaged Research Grant from the College of Health Sciences and Professions at Ohio University.

\section{Declaration of Interest}

The authors declare that they have no non-financial or financial conflict of interest.

\section{REFERENCES}

1. Datillo J, Kleiber D, Williams R. Self-determination, enjoyment and enhancement: a psychologically-based service delivery model for therapeutic recreation. Ther Recreation J. 1998;12:258-271.

2. Datillo J, Estrella G, Estrella LJ, Light J, McNaughton D, Seabury M.
I have chosen to live life abundantly: perceptions of leisure by adults who use augmentative and alternative communication. Augment Altern Commun. 2008;24:16-28.

3. Majnemer A, Shikako-Thomas K, Chokron N, Law M, Shevell M, Chilingaryan $\mathrm{G}$, et al. Leisure activity preferences for 6-12-yearold children with cerebral palsy. Dev Med Child Neurol. 2010;52: 167-173.

4. Patterson I, Pegg S. Serious leisure and people with intellectual disabilities: benefits and opportunities. Leisure Studies. 2009;28: 387-402.

5. Stancliffe RJ, Larson S, Auerback K, Engler J, Taub S, Lakin C. Individuals with intellectual disabilities and augmentative and alternative communication: analysis of survey data on uptake of aided AAC, and loneliness experiences. Augment Altern Commun. 2010; 26:87-96.

6. Chun S, Lee Y, Lundberg N, McCormick B, Heo J. Contribution of community integration to quality of life for participants of community-based adaptive sport programs. Ther Recreation J. 2008; 42:217-226.

7. Kleiber D, Reel H, Hutchinson S. When distress gives way to possibility: the relevance of leisure in adjustment to disability. NeuroRehabilitation. 2008;23:321-328.

8. Hawkins BL, Ryan JB, Cory AL, Donaldson MC. Effects of equine assisted therapy on gross motor skills of two children with autism spectrum disorder. Ther Recreation J. 2014;48:135-149.

9. Zabriskie RB, Lundberg NR, Groff DG. Quality of life and identity: the benefits of a community based therapeutic recreation and adaptive sports program. Ther Recreation J. 2005;39:176-191.

10. Light J. Shattering the silence: development of communicative competence by individuals who use AAC. In Light JC, Beukelman DR, \& Reichle J, editors. Communicative competence for individuals who use AAC: From research to effective practice. Baltimore, MD: Paul H. Brookes; 2003 [cited 2018 Sep 24].

11. Datillo J, Benedek-Wood E, McLeod L. Activity brings community into our lives: Recreation, leisure and community participation for individuals who use AAC. In McNaughton D \& Beukelman DR, editors. Transition strategies for adolescents \& young adults who use AAC. Baltimore, MD: Paul H. Brookes; 2010 [cited 2018 Sep 24].

12. Mirenda P. Re-visiting the mosaic of supports required for including people with severe intellectual or developmental disabilities in their communities. Augment Altern Commun. 2014;30:19-27.

13. Batorowicz B, Campbell F, Von Tetzchner S, King G, Missiuna C. Social participation of school-aged children who use communication aids: the views of children and parents. Augment Altern Commun. 2014;30:237-251.

14. Batorowicz B, McDougall S, Shepherd TA. AAC and community partnerships: the participation path to community inclusion. Augment Altern Commun. 2006;22:178-195.

15. Hamm B, Mirenda P. Post-school quality of life for individuals with developmental disabilities who use AAC. Augment Altern Commun. 2006;20:134-147.

16. Datillo J, Light J. Setting the stage for leisure: encouraging recipro- 
cal communication for people using augmentative and alternative communication systems through facilitator instruction. Ther Recreation J. 1993;27:156-171.

17. Kent-Walsh J, McNaughton D. Communication partner instruction in AAC: present practices and future directions. Augment Altern Commun. 2005;21:195-204.

18. Hajjar D, McCarthy J, Benigno J, Chabot J. You get more than you give: experiences of community partners in facilitating active recreation with individuals who have complex communication needs. Augment Altern Commun. 2016;32:131-142.

19. Lockstone-Binney L, Holmes K, Smith K, Baum T. Volunteers and volunteering in leisure: social science perspectives. Leisure Studies. 2010;29:435-455.

20. Collier V, Rothwell E, Vanzo R, Carbone PS. Initial investigation of comfort levels, motivations, and attitudes of volunteers during therapeutic recreation programs. Ther Recreation J. 2015;49:207219.

21. Lundberg N, Bennet J, Smith S. Outcomes of adaptive sport and recreation participation among veterans returning from combat with acquired disability. Ther Recreation J. 2011;45:105-120.

22. McAvoy L, Smith JG, Rynders JE. Outdoor adventure programming for individuals with cognitive disabilities who present serious accommodation challenges. Ther Recreation J. 2006;40:182199.

23. Binger C, Kent-Walsh J, Ewing C, Taylor S. Teaching educational assistants to facilitate the multisymbol message productions of young students who require augmentative and alternative communication. Am J Speech Lang Pathol. 2010;19:108-120.

24. Meline T. A research primer for communication sciences and disorders. 1st ed. Boston: Pearson Education Inc.; 2010 [cited 2018 Sep 24].

25. Dunn LM, Dunn LM. Peabody Picture Vocabulary Test-Revised. Circle Pines, MN: American Guidance Service, Inc.; 1981 [cited 2018 Sep 24].

26. Viera A, Garrett J. Understanding interobserver agreement: the kappa statistic. Fam Med. 2005;37:360-363.

27. McReynolds LV, Thompson CK. Flexibility of single-subject experimental design, Part I: Review of the basics of single-subject designs. J Speech Hear Disord. 1986;51:194-203.

28. Vannest KJ, Parker RI, Gonen O, Adiguzel T. Single case research web based calculators for SCR analysis (Version 2.0) [Web-based application]. College Station, TX: Texas A \& M University; 2016 [cited 2018 Sep 24]. Available from: singlecaseresearch.org

29. Light J, McNaughton D. Communicative competence for individuals who require augmentative and alternative communication: a new definition for a new era of communication? Augment Altern Commun. 2014;30:1-18.

30. Light J, McNaughton D. Designing AAC research and intervention to improve outcomes for individuals with complex communication needs. Augment Altern Commun. 2015;31:85-96. 


\section{Appendix A}

\section{Scoring Rubric}

\begin{tabular}{|c|c|c|}
\hline Purpose/step & Volunteer role & Points \\
\hline 1. CALL & Announce "okay (name of rider, its time to pick your take away)" & 1 \\
\hline \multirow[t]{2}{*}{ 2. CHOOSE } & $\begin{array}{l}\text { Offers three different options; movie, photo or bucket items. } \\
\text { "Do you want to make a movie (point to camera), take a picture (point to camera), or pick from the bucket } \\
\text { (point to the bucket)?" }\end{array}$ & $\begin{array}{l}3 \\
\text { For each choice offerec } \\
\text { gets } 1 \text { point }\end{array}$ \\
\hline & $\begin{array}{l}\text { Respond appropriately: This means that the volunteer noticed a choice was made and moved on to the next } \\
\text { step. }\end{array}$ & $t 1$ \\
\hline 3. CONFIRM & Volunteer confirms the item selected by the rider ("you picked ....") & 1 \\
\hline \multirow[t]{2}{*}{ 4. CONSIDER } & $\begin{array}{l}\text { Depending on what the rider selected; volunteer asks a "What" question (what to take movie/photo of), } \\
\text { what sticker, what stamp, what other miscellaneous item? }\end{array}$ & 1 (for asking question) \\
\hline & $\begin{array}{l}\text { Does Volunteer respond appropriately to riders' selection? Does the volunteer recognize the response and } \\
\text { move on? }\end{array}$ & 1 \\
\hline \multirow[t]{2}{*}{ 5. CAPTURE } & Who question. Volunteer asks: "Who will take movie/photo or will hold items?" & 1 (for asking question) \\
\hline & $\begin{array}{l}\text { Does volunteer respond appropriately and take action? (i.e. recognize rider response and then facilitate } \\
\text { taking photo, movie or giving item to person). }\end{array}$ & 1 \\
\hline 6. COMPLIMENT & Volunteer gives a compliment about photo, movie or item selected from the bucket. & 1 \\
\hline
\end{tabular}




\section{Appendix B}

\section{Operational Definitions for Topic Reliability}

1. Riding and lesson activity: this category includes any turns related to the horse or the lesson activities that may involve the horse; responses from riders may be verbal or non-verbal (gestures, head nods, pointing etc); these turns include lesson related directives and responses from the riders when engaged in a lesson related task or responding to a horse or lesson related task.

2. Intervention program: this category includes any turns that are related to the take-home intervention script; also any turns that involve discussion about the items selected during the take home program. For example, if rider and volunteer are discussing the subject for a photo or video, or waiting for a photo to be printed. Do not count turn related to technical difficulties that may occur with the video or digital camera, these will be tracked as a separate topic area.

Operational/technical: this includes any turns that involve discussion about if the cameras are not working or if the volunteer talks to the rider about the cameras not working. This does not include turns between the volunteer and instructor or other volunteers on the lesson; only turns between the rider and volunteer.

\section{Social}

Small/personal talk: this includes turns related to anything outside of horse/activity and take-home turns. Examples here may be discussions about what occurred over the weekend or what may be occurring over the upcoming weekend.

Greetings/Social: this includes turns related to opening or closing greetings between the volunteer and rider but NOT with the horse. If the rider says hi/bye to the horse, then that would be considered "horse/lesson talk".

\section{Other}

Not codable: if you are unable to find a category to fit a turn in, this is where it would go.

\section{Helpful hints:}

If a turn is completely unintelligible, then do not count it, but if only a portion of the turn is unintelligible and you can determine that the response or initiation is related to one of the topic areas then go ahead and count it.

Only count turns between the volunteer and the rider; not when the volunteer speaks to the instructor or another volunteer. 